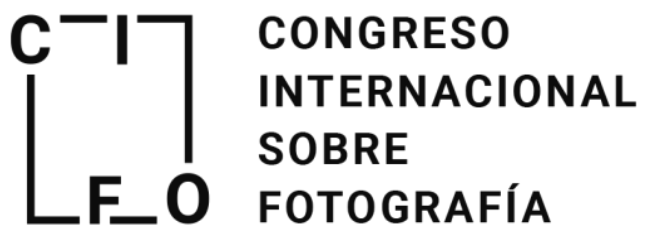

Congreso Internacional sobre Fotografía

UPV, 5 y6 octubre 2017

Doi: http://dx.doi.org/10.4995/CIFo17.2017.6740

ISBN: 978-84-9048-604-7

\section{Walker Evans y Europa. La influencia de las vanguardias en el estilo documental norteamericano.}

\section{Jorge Pulla González}

Universidad de Alicante, Departamento de Humanidades Contemporáneas, jorge.pulla@ua.es

\begin{abstract}
Walker Evans (1903-1975) is considered the founder of the American "documentary style". In this communication we will indicate the European sources from which this style arose, among them is the literature and photography of the margins of the avant-gardes, especially French surrealism. We will show how Evans's photography emerges in an almost totally European environment and drinks from two completely different sources:

In the first place the literature, especially the French literature embodied in two fundamental figures: the poet Baudelaire, from who he will extract the flâneur's spirit, and Flaubert, a key figure of exacerbated realism.

In second place the photography, whose most direct references are Brady and, especially, the French Atget, with whose work he made contact in environments very influenced by the surrealism. He also partially assimilated strategies of Soviet and German avant-garde constructivist photography, especially in his studies of the geometric potentialities of large architectural structures.
\end{abstract}

\section{Keywords:}

Photography, documentary style, avant-garde, literature, Europe, Walker Evans.

\section{Resumen}

Walker Evans (1903-1975) es considerado el iniciador del "estilo documental" norteamericano. A lo largo de esta comunicación indicaremos las fuentes europeas de las que este surgió, entre las que se encuentra la literatura y la fotografía del entorno de las vanguardias, en especial del surrealismo francés. Mostraremos cómo la fotografía de Evans surge en un medio totalmente europeo y bebe de dos fuentes completamente distintas:

En primer lugar está la literatura, especialmente la literatura francesa encarnada en dos figuras fundamentales: el poeta Baudelaire, del cual extraerá el espíritu propio del flâneur, y Flaubert, figura clave del realismo exacerbado. 
Walker Evans y Europa. La influencia de las vanguardias en el estilo documental norteamericano.

En segundo lugar, la fotografía, cuyos referentes más directos son Brady y, especialmente, el francés Atget, con cuya obra entabló contacto en ambientes muy influidos por el surrealismo. También asimiló parcialmente estrategias de la fotografía constructivista soviética y alemana de vanguardia, especialmente en sus estudios de las potencialidades geométricas de las grandes estructuras arquitectónicas.

Palabras clave: Fotografia, estilo documental, vanguardias, literatura, Europa, Walker Evans.

\section{Texto}

Walker Evans (1903-1975) es una figura central de lo que se ha llamado el "estilo documental", en especial por el papel que tuvo en el seno del proyecto emprendido por la Farm Security Administration en EE.UU. La Farm Security Administration (F.S.A.), una agencia gubernamental fundada en 1935 dentro del espíritu del New Deal, desarrolló una importante labor de investigación y documentación fotográfica de la pobreza rural surgida de la Gran Depresión y de las tormentas de polvo que azotaron extensas zonas de Estados Unidos durante los años treinta.

Dirigida por el sociólogo Roy Stryker, se fundó en un primer momento con los fotógrafos Arthur Ronstein, Carl Mydans, Ben Shahn y Walker Evans; más tarde se unieron al grupo Dorothea Lange y otros hasta su cierre definitivo en 1943. Walker Evans fue despedido en 1937 por sus enfrentamientos con Stryker, pero su trabajo constituye el núcleo del proyecto y la base de su estilo. A lo largo de esta comunicación mostraremos las fuentes de las que este surgió, entre las que se encontrará la literatura y la fotografía del entorno de la vanguardia literaria francesa.

Walker Evans estableció una estrecha relación con la literatura francesa a través de sus lecturas: primero, en la biblioteca universitaria del Williams College y, más tarde, durante sus tres años de trabajo en la New York Public Library, una de las bibliotecas más importantes y con más fondos de los Estados Unidos y del mundo. En estas instituciones, "sediento de literatura de vanguardia, que por entonces se encontraba en su apogeo" (Bear, 2008, p. 15), leyó a Baudelaire, a Gide y al resto de los escritores franceses más innovadores. Esta relación se hizo más estrecha aún durante la larga estancia en París de la que disfrutó financiado por su padre durante los años 1926-1927 (Mora, 1989, p. 11). Durante ese tiempo intentó iniciar una carrera literaria, para lo cual se inscribió en la Sorbona bajo la figura de auditeur libre, muy común en las instituciones francesas. Sin embargo, volvió a América sin haber publicado ni una sola línea más allá de unas instructivas traducciones de Baudelaire y Blaise Cendrars (Bear, 2008, p. 16-17). Alejado de los círculos de expatriados (González, 2008, p. 47), tampoco entabló contacto con la llamada "generación perdida", el nutrido grupo de literatos norteamericanos que, en torno a la figura protectora de Gertrude Stein, se encontraban en París para beber de las fuentes europeas (y de paso aprovechar el ventajoso cambio del dólar frente a las divisas de este lado del Atlántico, que les permitía una vida material mucho más desahogada) ${ }^{1}$.

\footnotetext{
${ }^{1}$ El ambiente de esta "generación perdida" en París se encuentra perfectamente retratado en la novela de Hemingway París era una fiesta.
} 
Aunque la estancia en Francia no le reportó ningún beneficio a su casi inexistente prosa, su experiencia europea y el contacto con la vanguardia literaria que esta le procuró han de tenerse en cuenta a la hora de entender su desarrollo posterior como fotógrafo, hecho que la crítica norteamericana tiende a minusvalorar a la hora de analizar su obra, que prefiere entender como algo pura e intrínsecamente estadounidense (Mora, 1989, pp. 13 y 17). Pero Evans mismo desmiente este acercamiento a su trabajo:

\section{Mi generación es la primera que fue a Europa y adquirió una perspectiva y una técnica europeas y que volvió a América y las aplicó. [Como] Hemingway [...], que hablaba francés, italiano, español.}

- ¿Cuando comenzó a fotografiar, en qué medida se vio afectado por la atmósfera cultural y la fotografía que encontró en Nueva York al regresar?

Me encontré operando directamente desde la estética y la psicología frente al mundo francesas. Las aplicaba al problema de dar cuenta de lo que veía 2

En 1927 regresa a los Estados Unidos y se reinstala en Nueva York, abandonando definitivamente la escritura (Katz, 1971), pero muy marcado por ella; cuando comienza a fotografiar, la atención a los objetos comunes y a lo ordinario presentes en la literatura de las vanguardias serán inmediatamente el origen de las listas de temas de su trabajo, centrado, en línea con Mac Orlan ${ }^{3}$, Benjamin ${ }^{4}$ y el surrealismo, en "los desechos de lo cotidiano" (Bear, 2008, p. 17) y en los signos urbanos: la publicidad y las señales, los maniquíes..., también, sin duda tras haber asimilado el trabajo de la fotografía constructivista soviética y alemana de vanguardia, en estudios de las potencialidades geométricas de las grandes estructuras arquitectónicas.

Su trabajo llamó rápidamente la atención de su compañero de apartamento en Brooklyn, el poeta Hart Crane, que utilizó varias de sus fotografías para ilustrar el poemario The bridge. Crane, expatriado durante un tiempo también en Francia, se encontraba en estrecha relación con el círculo surrealista formado en torno a la pareja Harry y Caresse Crosby, círculo del que también fueron asiduos Crevel, Dalí, Breton o Cartier-Bresson ${ }^{5}$. En su finca Le Moulin du Soleil en Ermenonville, a las afueras de París, Crane redactó gran parte del poemario, que luego fue publicado en la editorial Black Sun Press, propiedad del matrimonio ${ }^{6}$.

Hart Crane también le presentó a Alfred Stieglitz ${ }^{7}$. El encuentro con Stieglitz constituyó, a la vez, un fracaso y un éxito. En primer lugar, un fracaso porque las fotografías de Evans no serán del agrado de Stieglitz, verdadero director del gusto del medio fotográfico norteamericano en ese momento; esto le cerrará las puertas del ámbito de la fotografía llamada "artística". En segundo lugar, un éxito porque ese encuentro dará a Evans una idea clara de todo aquello que no quiere hacer. El romanticismo estetizante y "artístico" de Stieglitz será aquello contra lo que Evans construirá su propio estilo:

Stieglitz me estimuló [...] en él encontré alguien contra quien trabajar (Katz, 1971).

\footnotetext{
${ }^{2}$ Katz, 1971. El artículo también está disponible en la recopilación The Camera Viewed (Petruck, 1979).

${ }^{3}$ Sobre Mac Orlan y su teoría de la fotografía, véase Pulla (2008)

${ }^{4}$ Para una explicación sucinta de las ideas sobre la fortografía desarrolladas por Benjamin a lo largo de toda su producción, véase Pulla (2009).

${ }^{5}$ Henri Cartier-Bresson desarrolló toda su obra de los años 30 dentro de los más estrictos cánones del surrealismo; sobre la teorización de la fotografía llevada a cabo por Cartier-Bresson, véase Pulla (2007).

${ }^{6}$ Diccionario literario en línea Dictionary of Literary Biography: http://www.bookrags.com/biography/harold-hart-crane-dlb/\#gsc.tab=0

${ }^{7}$ Alfred Stieglitz (1864-1946) fue un fotógrafo germanoestadounidense, cuyo impulso fundamental siempre fue defender la artisticidad de la fotografía. Asiduo de los círculos pictorialistas, pasó a ser uno de los primeros defensores de la llamada "straight photography" o "fotografía directa". Fundó el importante grupo Photo-Secession, dentro del cual publicó la fundamental revista Camera Work (1902-1917) y creó la galería 291, primera galería de arte de Estados Unidos, en la que se expusieron obras de artistas de la vanguardia francesa como Auguste Rodin, Henri Matisse, Paul Cézanne, Henri Rousseau, Constantin Brancusi o Pablo Picasso, incluidos los surrealistas Francis Picabia y Marcel Duchamp. Sobre Stieglitz y la galería 291, véase Doty (1978) y Stieglitz (2004).
} 
Sin duda, el desencuentro se debe a que las fuentes de Stieglitz y Evans son muy diferentes. Stieglitz proviene de un ambiente artístico, centrado en torno a la pintura, desde el que se dedica al problema de la artisticidad de la fotografía y su estatus como obra de arte, pero siempre en relación con la obra pictórica. Evans surge en un medio totalmente diferente, $\mathrm{y}$ bebe de dos fuentes completamente distintas.

En primer lugar, está la literatura, especialmente la literatura francesa encarnada en dos figuras fundamentales: el poeta Baudelaire ${ }^{8}$, del cual extraerá el espíritu propio del flâneur, y Flaubert, figura clave del realismo exacerbado9: "Flaubert me proporcionó un método, Baudelaire un espíritu" (Katz, 1971). El método de Flaubert será incorporado por Evans de modo natural, como una prolongación involuntaria de su fracasada actividad literaria:

Creo que incorporé el método de Flaubert casi inconscientemente, pero aun asi lo usé de dos maneras; tanto su realismo como su naturalismo, y su objetividad en el tratamiento. La no aparición del autor. La no subjetividad. Esto es literalmente aplicable a la forma en la que yo quiero usar y uso la cámara (Katz, 1971).

En segundo lugar, la fotografía, cuyos referentes más directos son $\operatorname{Brady}^{10} \mathrm{y}$, especialmente, Atget ${ }^{11}$. Con este último entró en contacto no en Francia, sino a través de su amistad con Berenice Abbott, la asistente del surrealista Man Ray en París, que en noviembre de 1929 se encontraba copiando los negativos comprados para Julien Levy en su estudio de Nueva York (Szarkowski, 1986, p. 82) y le regaló varias copias. El contacto con Atget se produjo justo en el momento en que Evans buscaba su vía en el medio fotográfico y este le mostró el camino a seguir, lejos de la fotografía afectada y artística de Stieglitz, como puede verse en las reseñas de textos sobre fotografía que publica en la revista Hound \& Horn, dirigida por Lincoln Kirstein:

Ciertos hombres del siglo pasado se han dado cuenta de que estaban lejos de esta confusión. Eugene Atget trabajó atravesando un periodo de decadencia absoluta en la fotografía. Simplemente estaba aislado, y su historia es un poco dificil de entender. [...] Su tono general es la comprensión lírica de la calle, la observación entrenada de la misma, una especial sensibilidad por la pátina, ojo para el detalle revelador, sobre los cuales lanza una poesía que no es "la poesía de la calle" o "la poesía de París", sino la proyección de la persona de Atget. (Evans, 1931)

Como hemos visto, las referencias iconográficas de Evans hay que buscarlas en los fotógrafos que han privilegiado el aspecto documental de su actividad, frente a los que se centran en la fotografía como forma de arte. El problema de la artisticidad de la fotografía no tiene en Evans relevancia, pero sí la tiene, y central, en la obra de otros americanos del momento, como Stieglitz, Strand, Steichen o Weston, de ahí la importancia que

\footnotetext{
${ }^{8}$ La influencia de Baudelaire, uno de los precursores del surrealismo es claramente afirmada por el propio Evans: "Baudelaire es para mí un Dios" (Katz, 1971).

9 "Un artista debe estar en su trabajo como Dios en la creación, invisible y todopoderoso; debe poder ser sentido en todas partes, pero no se le debe ver en ningún sitio. Además, el arte debe prevalecer por encima de las emociones personales y las susceptibilidades nerviosas. Es hora de dotarlo de un método despiadado, tan exacto como el de las ciencias físicas" (Steegmuller, 1953, p. 195).

${ }^{10}$ Mathew B. Brady (1823-1896) fue el fotógrafo más célebre de su momento en Estados Unidos gracias a las imágenes que su equipo de fotógrafos tomó durante la Guerra de Secesión. Puede ser considerado el primer reportero. Evans entrará en contacto con la obra de Brady a través de Lincoln Kirstein. Kirstein es una figura fundamental a la hora de entender la evolución del trabajo de Evans desde sus inicios mismos. A través de su revista Hound and Horn, ayudará a generar el estilo de fotografías típicamente americano de los años treinta, en parte a través de la puesta en valor del aspecto documental de la fotografía que, precisamente, Brady puso de relieve durante la Guerra de Secesión norteamericana.

${ }^{11}$ Evans fue uno de los primeros en constatar la importancia de Atget y su estilo para la fotografía (Galassi, 2000, p.13).
} 
estos dan a cuestiones de tipo técnico-estético. En Evans, los aspectos estéticos quedan de lado frente al valor testimonial de la imagen, como ocurría en Atget. Es gracias al conocimiento de la obra del fotógrafo francés que Evans descubriría el inmenso potencial de la fotografía descriptiva, una mirada al ser humano y la sociedad en la que lo anodino cobra tanta relevancia como lo extraordinario; de él extraería una comprensión de la práctica de la fotografía como acumulación y colección ${ }^{12} \mathrm{y}$, sobre todo, un reconocimiento de que la claridad en la percepción (común a la obra de ambos) no produce una simple objetividad banal, sino un misterio sumamente convincente (Galassi, P., 2000, 47).

La influencia de Atget, fusionada con el confesado espíritu de flânerie baudeleriano, es también manifiesta en la elección de los temas, tanto de su primera etapa productiva (1928-1931, centrada en Nueva York), como del resto de su obra, que gira, fundamentalmente, en torno a la ciudad y al "conocimiento lírico de la calle" (Bear, 2008, p. 19):

Sé que ahora es el momento de los libros de fotografias. Una ciudad americana es lo mejor, Pittsburgh mejor que Washington. Sé más sobre ella. Pero antes de decidirme por Pittsburg, me gustaría visitar otras. Tal vez algo más pequeño: Toledo, Ohio. Pero no estoy seguro de que un libro deba poder ser identificado localmente. Voy detrás de la ciudad americana. Tal vez deba usar varias, para llegar a lo típico. Podemos encontrar las cosas que buscamos en Pittsburg, Toledo, Detroit (muchas en Detroit, [...], Detroit está lleno de oportunidades). El distrito de negocios de Chicago, probablemente nada en Nueva York, pero las afueras de Philadephia son brumosas e infinitas:

Las gentes, todas las clases, rodeadas por montones de indigentes.

Los automóviles y su paisaje.

La arquitectura, el gusto urbano americano, el comercio, minorista, al por mayor, la atmósfera de las calles de la ciudad, el olor de la calle, su lado odioso, los clubes de mujeres, la cultura podrida, la mala educación, la religión en decadencia.

Las películas.

Evidencias de lo que la gente de la ciudad lee, come, ve para divertirse, hace para relajarse y evadirse.

Sexo.

Publicidad.

Muchas cosas más, ya sabe lo que quiero decir ${ }^{13}$.

Como señala Gilles Mora en su volumen sobre Evans (Mora, 1989, p. 26), la panoplia temática de este texto programático tiene claras analogías con la de Atget, también con las surrealistas estrategias creativas de André Breton en Nadja o Louis Aragon en Le Paysan de Paris, y constituye un proyecto antropológico o sociológico que surge de la profunda atracción de Evans por los aspectos sociales y humanos de la civilización moderna, que tiene su máxima expresión en la gran ciudad industrial y sus márgenes. Las manifestaciones culturales que en ella se expresan, como la publicidad o la arquitectura, son en Evans la puerta de entrada a un análisis de la civilización americana de entreguerras:

\footnotetext{
12 "P. - Usted es coleccionista; colecciona postales y objetos encontrados. ¿Hay alguna relación entre esto y su trabajo? R. - Mucha. Es casi lo mismo" (Katz, 1971). Evans compartirá la misma atracción por el coleccionismo y las postales de los surrealistas ( Evans, 1994, pp. 226231; Chéroux, 2017, 90, 190).

${ }_{13}$ Carta de febrero de 1934 (Evans, 1994, p. 98).
} 
Walker Evans y Europa. La influencia de las vanguardias en el estilo documental norteamericano.

La naturaleza me mata de aburrimiento, como un Eliot Porter o un Ansel Adams que la fotografien. Yo me intereso ante todo en la mano del hombre y la civilización ${ }^{14}$.

En esta atracción por la ciudad no se encuentra solo. Ya sabemos que es un tema común en su momento, en especial en el ámbito literario francés. A partir de Baudelaire la deambulación por la ciudad y la calle se encuentra en el centro de la actividad creativa, que se basa, fundamentalmente, en el errar a la búsqueda de la belleza escondida:

Como Atget o los surrealistas, Evans deambula [...], recogiendo rincones, los signos de la fábrica urbana, los tipos sociales de la ciudad, pero siempre sin un tema o una finalidad predeterminados. Asi [...] Evans produce un caleidoscopio de sensaciones urbanas (González, 2008, p. 53).

El mismo Kirstein nos señala cómo el proyecto de análisis social de Evans debe mucho al de Atget y se encuentra en la misma línea: Walker Evans nos está dando la civilización contemporánea del este de América y sus territorios, igual que Atget nos dio París antes de la guerra y Brady nos dio la guerra entre los estados (Kirstein, 1938, p. 193).

Esta influencia atgetiana se da también en aspectos formales, como puede verse especialmente en la fotografía de interiores, uno de sus temas favoritos:

Ninguna presencia humana directa: el mobiliario, los objetos, los utensilios, las fotos colgadas en la pared nos dicen más sobre la psicología social de sus habitantes de lo que lo haría su presencia en la imagen. [...] Al término del inventario al que se invita a la mirada, sabemos tanto [sobre los habitantes del interior], su condición racial y social, como con la lectura de una larga descripción sociológica (Mora, 1989, pp. 76-77).

La coincidencia formal (frontalidad cada vez más acusada, serialidad, altura de la cámara fijada por la del trípode) se hará total cuando Evans use la cámara de placas de gran formato. Al igual que en Atget, cada fotografía de Evans forma una unidad por sí misma, pero existe una intención clara de realizar una colección, una serie unificada por aspectos formales y temáticos. Y también ambos comparten una implicación de tipo moral en ese afán recolector y acumulador.

Sin embargo, y esto es fundamental, la principal enseñanza teórica que Evans extraerá de Atget será la plena conciencia de la surrealista ambigüedad que entraña el estilo documental:

Al parecer, solo prestaba atención a la necesidad de fotografiar París y sus alrededores; pero exactamente qué visión tenía del monumento que dejaba no está claro. Es posible leer en sus fotografias tantas cosas que puede no haberse nunca formulado a sí mismo. En algunos de sus trabajos incluso se sitúa en una posición en la que se le lanzaría encima el más ortodoxo de los surrealistas. (Evans, 1931)

\footnotetext{
${ }^{14}$ Entrevista inedita con Walker Evans realizada en 1974 por Jeffrey W. Limerick (Mora, 1989, p. 27).
} 
Evans cultivará esta ambigüedad toda su vida, constituyendo parte fundamental de su forma de entender la fotografía:

[Cuando se dice “documental”], se debe tener un oido sofisticado para recibir esa palabra. El término adecuado es estilo documental. Un ejemplo de documento literal es una fotografía policial de la escena de un asesinato. Un documento tiene un uso, mientras que el arte no tiene ninguna utilidad. El arte no es nunca un documento, pero puede adoptar su estilo. A veces se me llama "fotógrafo documental". Pero eso presupone un muy sutil conocimiento de la distinción que acabo de hacer [...]. Alguien trabajando bajo esa etiqueta puede tomar un astuto placer disfrazándose. A menudo, yo hago una cosa cuando todo el mundo cree que estoy haciendo otra (Katz, 1971).

Así pues, la influencia de Atget es fundamental en la génesis del concepto central de la estética de Evans, la forma de fotografiar que Evans llamará el "estilo documental" y que se encuentra en su trabajo desde sus mismos inicios:

Yo estaba bastante seguro de ello entonces, sí. Estaba seguro de que estaba trabajando en el estilo documental. Sí, y yo estaba haciendo historia social, hablando en términos generales ${ }^{15}$.

Evans integró en su proyecto fotográfico, más allá de Atget, los resultados de las vanguardias históricas, especialmente del surrealismo y no tanto de las tendencias constructivistas; a pesar de su utilización de cámaras diseñadas para utilizarse sin trípode (una cámara de rollo, poco después una Leica $^{16}$ ), los pocos ejemplos que encontramos en su obra de estos años de imágenes influidas por los planteamientos formales del constructivismo (diagonales, picados, contrapicados, tan queridos, por ejemplo, a Rodchenko) o el cubismo se producen, precisamente, antes de su crucial encuentro con la obra de Atget en noviembre de 1929, que marcaría un antes y un después en su producción. A partir de ese encuentro, la coincidencia con el surrealismo y sus fotógrafos afines se plasmará, sobre todo, en su gran interés por las tomas simples de calles, los habitantes del espacio urbano y los signos que ocultan, en especial por las mujeres, en los bares, los restaurantes, en conversación ante los escaparates de las tiendas, fuera de cuadro, en pareja, perdidas en el movimiento del gentio, arropadas en sus visones o tocadas con sombreritos sorprendentes[;] las mujeres llenan con sus rostros y sus siluetas las imágenes de Evans (Mora, 1989, p. 30). El surrealismo seguirá presente en su trabajo de madurez: primacía del trabajo de calle, un sentido de la imagen que la concibe casi como un collage (construyéndola en muchas ocasiones sobre la superficie de los muros, como hace también el plenamente surrealista Cartier-Bresson de los años 30), y una gran atracción por lo extraño y degradado que le lleva a hacer de lo vernáculo el centro temático de su estilo documental.

\section{Referencias}

\footnotetext{
${ }^{15}$ Entrevista acerca del trabajo realizado en Cuba en 1933 (Evans, 1994, p. 82).

${ }^{16}$ Después comenzó a utilizar una cámara de gran formato, en un itinerario contrario al de muchos de los fotógrafos del momento, que pasaron de la canónica cámara de placas al formato, más manejable, de $35 \mathrm{~mm}$ o a cámaras de formato medio. Sin embargo, nunca abandonó la cámara portátil en ninguno de sus formatos, y no puede decirse que Evans privilegiara el uso de la cámara de placas frente a las cámaras más pequeñas en ninguna etapa de su actividad creativa (Evans, 1994, 10).
} 
Walker Evans y Europa. La influencia de las vanguardias en el estilo documental norteamericano.

BEAR, J. (2008). "Walker Evans: en el reino de lo cotidiano" en Evans, W. et al. Walker Evans, Madrid: Fundación MAPFRE. pp. 15-39.

ChÉroux, C., ed. (2017). Walker Evans. París: Centre Pompidou.

Crane, H. (1930). The bridge. París: Black Sun Press.

Dictionary of Literary Biography: http://www.bookrags.com/biography/harold-hart-crane-dlb/\#gsc.tab=0

Doty, R. (1978). Photo-secession. Stieglitz and the fine-art movement in photography. New York: Dover.

Evans, W. (1931). “The Reappearance of photography” en Hound \& Horn. Vol. 5, no. I, October-December, pp. 125-128.

Evans, W. et al. (1938). Walker Evans: American Photographs. Nueva York: MOMA.

Evans, W. et al. (1994). Walker Evans at Work. Nueva York: HarperCollins Publishers.

EvAns, W. et al. (2008). Walker Evans. Madrid: Fundación MAPFRE.

Galassi, P. (2000). Walker Evans \& Company. Nueva York: MoMA.

GonZÁLEZ, Ch. (2008). "Walker Evans y la invención del estilo documental” en Evans, W. et al. Walker Evans, Madrid: Fundación MAPFRE. pp. 41-65.

Hemingway, E. (1985). París era una fiesta. Barcelona: Seix Barral.

KATZ, L. (1971). “Interview with Walker Evans” en Art in America. Nueva York. Marzo-abril.

KirSteIn, L. (1938). "Photographs of America: Walker Evans" en Evans, W. et al. Walker Evans: American Photographs. Nueva York: MOMA. p. 193.

MorA, G. (1989). Walker Evans. París, Belfond/ Paris Audiovisuel, p. 11.

Petruck, P.R. (ed.) (1979). The Camera Viewed. Writings on Twentieth Century Photography. Nueva York: Dutton.

Pulla, J. (2007). "Estética y técnica del instante decisivo. La fotografía según Henri Cartier-Bresson", en Actas del Segundo Congreso de Historia de la Fotografia, Zarautz: Photomuseum, 2007, pp. 273-284.

Pulla, J. (2008). "Pierre Mac Orlan, lo "fantástico social" y la fotografía documental francesa de entreguerras", en Actas del Tercer Congreso de Historia de la Fotografia, Zarautz: Photomuseum, 2008, pp.159-169.

Pulla, J. (2009). "Walter Benjamin: el surrealismo y su fotografía en el origen de las nuevas funciones sociales del arte", en Actas del XVII Congrès Valencià de Filosofia, Valencia: Universidad de Valencia / Societat de Filosofia del País Valencià, 2009, pp. 309-317.

SteEgmuller, F. (ed.) (1953). The selected letters of Gustave Flaubert. Nueva York: Farrar, Straus \& Young, Inc.

Stieglitz, A. et al. (2004). Nueva York y el arte moderno: Alfred Stieglitz y su círculo (1905-1930). París/Madrid: Musée d'Orsay Réunion des musées nationaux/Museo Nacional Centro de Arte Reina Sofía.

SzARkowski, J. (1986), “Atget en Amérique” en Photographies. no especial sobre el Colloque Atget desarrollado en el Collège de France. París: Hazan, marzo, p. 82-86.

Trachtenberg, A. (1980). Classic Essays on Photography. New Haven: Leete's Island Books. pp. 185-188. 